Wright State University

CORE Scholar

Physics Faculty Publications

Physics

7-1-2011

\title{
Thermal Annealing Effect on Spin Coherence in ZnO Single Crystals
}

Z. Yang

David C. Look

Wright State University - Main Campus, david.look@wright.edu

H. M. Zhou

W. V. Kawakami

R. K. Kawakami

See next page for additional authors

Follow this and additional works at: https://corescholar.libraries.wright.edu/physics

Part of the Physics Commons

\section{Repository Citation}

Yang, Z., Look, D. C., Zhou, H. M., Kawakami, W. V., Kawakami, R. K., Yu, P. K., \& Liu, J. L. (2011). Thermal Annealing Effect on Spin Coherence in ZnO Single Crystals. Journal of Applied Physics, 110 (1), 16101. https://corescholar.libraries.wright.edu/physics/168

This Article is brought to you for free and open access by the Physics at CORE Scholar. It has been accepted for inclusion in Physics Faculty Publications by an authorized administrator of CORE Scholar. For more information, please contact library-corescholar@wright.edu. 


\section{Authors}

Z. Yang, David C. Look, H. M. Zhou, W. V. Kawakami, R. K. Kawakami, P. K. L. Yu, and J. L. Liu 


\title{
Thermal annealing effect on spin coherence in $\mathrm{ZnO}$ single crystals
}

\author{
Z. Yang, ${ }^{1, a), b)}$ Y. Li, ${ }^{2}$ D. C. Look, ${ }^{3}$ H. M. Zhou, ${ }^{1}$ W. V. Chen, ${ }^{4}$ R. K. Kawakami, ${ }^{2}$ P. K. L. Yu, ${ }^{4}$ \\ and J. L. Liu ${ }^{1, c)}$ \\ ${ }^{1}$ Quantum Structures Laboratory, Department of Electrical Engineering, University of California at Riverside, \\ Riverside, California 92521, USA \\ ${ }^{2}$ Department of Physics and Astronomy, University of California, Riverside, California 92521, USA \\ ${ }^{3}$ Semiconductor Research Center, Wright State University, Dayton, Ohio 45435, USA \\ ${ }^{4}$ Department of Electrical and Computer Engineering, University of California, San Diego, La Jolla, \\ California 92093, USA
}

(Received 21 November 2010; accepted 24 May 2011; published online 6 July 2011)

\begin{abstract}
The spin coherence time $\left(T_{2}{ }^{*}\right)$ in $\mathrm{ZnO}$ single crystals at $8.5 \mathrm{~K}$ decreases significantly from $\sim 11.2 \mathrm{~ns}$ to $\sim 2.3 \mathrm{~ns}$ after annealing at $500^{\circ} \mathrm{C}$, as indicated by time-resolved Kerr-rotation pump-probe magneto-optical spectroscopy. The annealing-induced spin coherence degradation in $\mathrm{ZnO}$ arises neither from crystallinity degradation during the annealing process, as confirmed by x-ray rocking curves; nor from reflection variations of the probe laser beam induced by surface roughness changes during the annealing process, as confirmed by atomic force microscopy. Temperature-dependent Hall-effect studies indicate that decreased mobility and increased shallow-donor concentration in the annealing-induced surface conducting layer on top of the bulk $\mathrm{ZnO}$ are most likely to be the reasons for the spin coherence degradation in $\mathrm{ZnO}$ during the annealing process. (C) 2011 American Institute of Physics. [doi:10.1063/1.3601869]
\end{abstract}

$\mathrm{ZnO}$-based materials have great potential ${ }^{1}$ in the areas of optoelectronics $^{2-5}$ and spintronics ${ }^{6}$ because of a direct bandgap, large exciton binding energy, ${ }^{1}$ and both theoretically predicted $^{7}$ and experimentally observed ${ }^{8-10}$ above-room-temperature Curie temperature. For spintronic applications, spin coherence is a critically important parameter. Experimental studies of spin coherence in $\mathrm{ZnO}$ were first reported by Ghosh et al. ${ }^{11}$ using time-resolved Faraday rotation (TRFR) pumpprobe magneto-optical spectroscopy, with an observation of a spin coherence time as long as $\sim 20 \mathrm{~ns}$ at $T=30 \mathrm{~K}$ in bulk $\mathrm{ZnO}$ samples. More recent experimental studies have shown an improvement in the spin coherence time in $\mathrm{ZnO}$ with an applied in-plane electric field confirmed by TRFR ${ }^{12}$ and spin dynamics in $\mathrm{ZnO}$ quantum dots using $\mathrm{TRFR}^{13}$; theoretical works have studied mechanisms of spin dynamics in ZnO. ${ }^{14,15}$ Many $\mathrm{ZnO}$ device applications, e.g., those requiring Ohmic contacts, involve an annealing step, ${ }^{2-5,16}$ and it is not clear yet how spin coherence properties change during annealing. In this letter, spin coherence changes during annealing are reported and discussed.

Three identical high-quality $\mathrm{ZnO}$ single crystal samples kept un-annealed and annealed at $500{ }^{\circ} \mathrm{C}$ and $800^{\circ} \mathrm{C}$ (for 2 min under $\mathrm{N}_{2}$ ambient in a rapid-thermal-annealing oven) were employed in this study. The three samples are labeled as A-C, as shown in Table I. Time-resolved Kerr rotation (TRKR) pump-probe magneto-optical spectroscopy was employed to investigate the electron spin dynamics, ${ }^{17}$ with $\sim 360 \mathrm{~nm}$ wavelength used for both pump and probe

\footnotetext{
${ }^{\text {a)} E l e c t r o n i c ~ m a i l: ~ z y a n g @ s e a s . h a r v a r d . e d u . ~}$

${ }^{b)}$ Present address: School of Engineering and Applied Sciences, Harvard University, Cambridge, MA 02138, USA.

${ }^{c)}$ Author to whom correspondence should be addressed. Electronic mail: jianlin@ee.ucr.edu.
}

laser sources, which matches $\mathrm{ZnO}$ bandgap $(\sim 3.437 \mathrm{eV}$ at $T<10 \mathrm{~K})$. Figure 1 shows the TRKR angle $\theta_{\mathrm{K}}$ as a function of time delay $\Delta t$ of samples A (top), B (middle), and C (bottom) measured at a temperature of $8.5 \mathrm{~K}$ and a magnetic field of $B=90 \mathrm{mT}$. The spin coherence times $T_{2}^{*}$ of each sample shown in Fig. 1 are obtained by fitting $\theta_{\mathrm{K}} \sim \Delta t$ relation using the equation

$$
\theta_{\mathrm{K}}(\Delta t)=A \cos \left(\omega_{\mathrm{L}} \Delta t\right) \exp \left(-\Delta t / T_{2}^{*}\right) .
$$

The solid lines in Fig. 1 show the fitting curves. The other two fitting parameters, amplitude $A$ and spin precession Larmor frequency $\omega_{\mathrm{L}}$, are summarized in Table I together with $T_{2}^{*}$ for all three samples. The effective electron $g$-factor $g^{*}$ of each sample is calculated using the equation

$$
\omega_{\mathrm{L}}=g^{*} \mu_{B} B / \hbar
$$

and shown in Table I, where $\mu_{B}$ and $\hbar$ are Bohr magneton and Planck constant, respectively. The spin coherence time decreased from $\sim 11.2 \mathrm{~ns}$ in sample $\mathrm{A}$, to $\sim 2.3 \mathrm{~ns}$ in sample $\mathrm{B}$, and finally to $\sim 2.0 \mathrm{~ns}$ in sample $\mathrm{C}$, while $g^{*}$ does not change much. The significantly decreased spin coherence time between unannealed $\mathrm{ZnO}(\sim 11 \mathrm{~ns})$ and annealed $\mathrm{ZnO}$ ( $\sim 2 \mathrm{~ns}$ ) samples indicates that additional spin scattering centers are formed during the annealing process. At elevated measurement temperatures, no analyzable spin coherence oscillation was obtained within the detection limit of the TRKR setup.

$\mathrm{X}$-ray rocking curves (XRCs) were performed on the $\mathrm{ZnO}$ (0002) peaks (at $2 \theta \sim 34.7^{\circ}$, which dominates in the $\theta-2 \theta$ x-ray diffraction patterns ${ }^{5}$ ) to investigate the crystallinity $^{5,18}$ of samples A, B, and C, respectively, as shown with top, middle, and bottom curves in Fig. 2. The full-width-athalf-maximum (FWHM) of the XRC curves, obtained from 
TABLE I. Sample preparations and spin-coherence parameters.

\begin{tabular}{lccccc}
\hline \hline Sample & $\begin{array}{c}t_{\text {Annealing }} \\
\left({ }^{\circ} \mathrm{C}\right)\end{array}$ & $\begin{array}{c}T_{2}^{*} \\
(\mathrm{~ns})\end{array}$ & $\begin{array}{c}\mathrm{A} \\
\left(10^{-3} \text { counts }\right)\end{array}$ & $\begin{array}{c}\omega_{L} \\
(\mathrm{GHz})\end{array}$ & $g^{*}$ \\
\hline A & un-annealed & 11.2 & 5.36 & 16.6 & 2.10 \\
$\mathrm{~B}$ & 500 & 2.34 & 4.18 & 16.3 & 2.06 \\
$\mathrm{C}$ & 800 & 2.00 & 2.20 & 16.5 & 2.08 \\
\hline \hline
\end{tabular}

standard Gaussian fitting, decreases slightly from $\sim 68$ arc sec (sample A), to $\sim 54$ arc sec (sample B) and $\sim 65$ arc sec (sample $\mathrm{C}$ ) after annealing. This indicates that the $\mathrm{ZnO}$ crystallinity does not degrade but actually improves slightly after annealing. Surface roughness may affect the reflection of the probe laser beam in TRKR measurements; however, atomic force microscopy (AFM) studies do not show any significant surface roughness changes in the annealed $\mathrm{ZnO}$ samples, with a root-mean-square roughness of $\sim 1 \mathrm{~nm}$ for all three samples. The inset in Fig. 2 shows a $2-\mu \mathrm{m} \times 2-\mu \mathrm{m}$ AFM image of sample A. So, neither crystallinity degradations nor surface roughness changes during annealing should be responsible for the spin coherence degradation in $\mathrm{ZnO}$. In order to clarify the origin of the annealing-induced spin coherence degradation in $\mathrm{ZnO}$, temperature-dependent Halleffect measurements and two-layer fittings ${ }^{17,19-21}$ were performed on the unannealed and annealed $\mathrm{ZnO}$ samples.

Figures 3(a) and 3(b) show the temperature dependence of the electron carrier concentration and mobility of samples A (squares), B (circles), and C (triangles) from 20 to $320 \mathrm{~K}$. The symbols and the solid lines are the experimental data

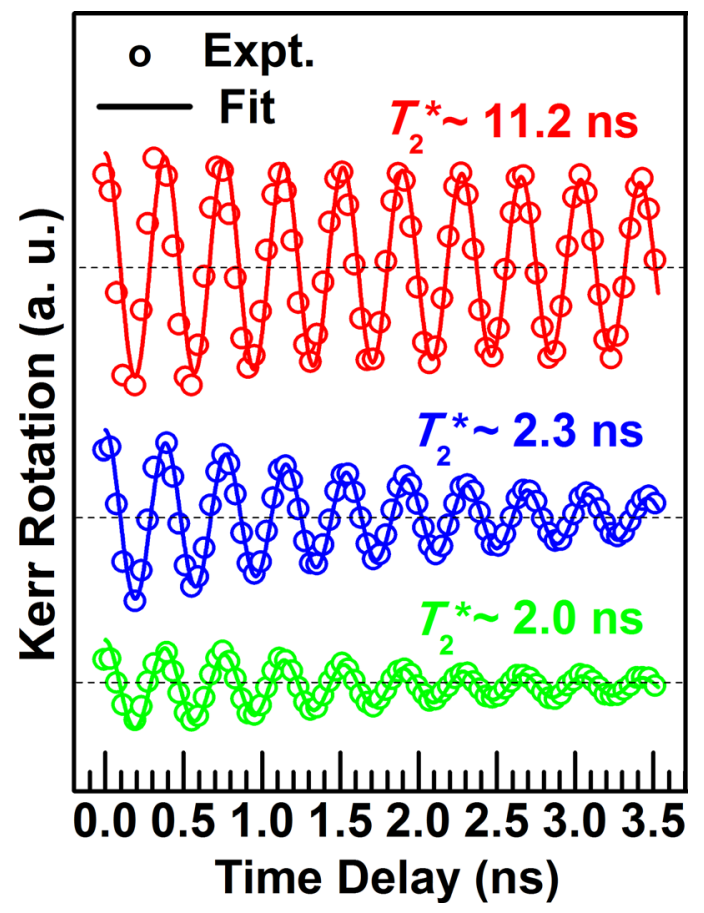

FIG. 1. (Color online) Time-resolved Kerr rotation of samples A (top), B (middle), and $\mathrm{C}$ (bottom) measured at $8.5 \mathrm{~K}$ and $90 \mathrm{mT}$. The circles and the solid lines represent experimental data and theoretical fits, respectively. The spin coherence time $T_{2}{ }^{*}$ obtained from fitting is $\sim 11.2, \sim 2.3$, and $\sim 2.0 \mathrm{~ns}$ for samples A, B, and C, respectively. The curves are vertically shifted for clarity and the black dashed lines show the zeros of each curve.

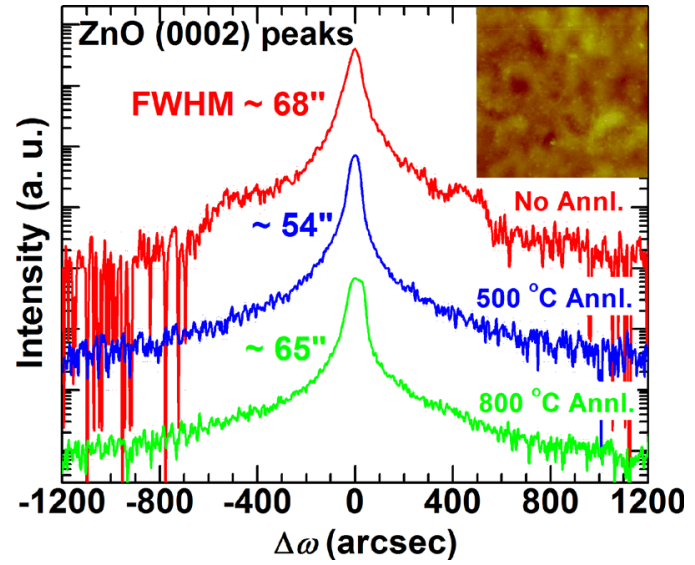

FIG. 2. (Color online) X-ray rocking curves of the $\mathrm{ZnO}$ (0002) peaks from samples A (top), B (middle), and C (bottom) measured at room temperature with FWHMs of $\sim 68, \sim 54$, and $\sim 65$ arc sec, respectively. The inset shows the AFM image of sample A within a $2 \mu \mathrm{m} \times 2 \mu \mathrm{m}$ area.

and theoretical fits, respectively. The fitting parameters are summarized in Table II. The most significant changes from sample A to B are those involving the surface conducting layer on top of the bulk layer: a thickness $\left(d_{\text {surf }}\right)$ decrease (120 down to $19 \mathrm{~nm})$, carrier concentration $\left(n_{\text {surf }}\right)$ increase $\left(2 \times 10^{17}\right.$ up to $\left.1 \times 10^{19} \mathrm{~cm}^{-3}\right)$, and mobility $\left(\mu_{\text {surf }}\right)$ decrease (1000 down to $230 \mathrm{~cm}^{2} \mathrm{~V}^{-1} \mathrm{~s}^{-1}$ ). Much smaller changes occur in the bulk donor and acceptor concentrations. The laser penetration depth in $\mathrm{ZnO}$ is around $60-100 \mathrm{~nm}^{22,23}$ For sample A, the laser absorption is mostly in the surface layer $(120 \mathrm{~nm})$, but the surface layer of sample $\mathrm{A}$ is of better "quality" than the surface layers of the annealed samples,
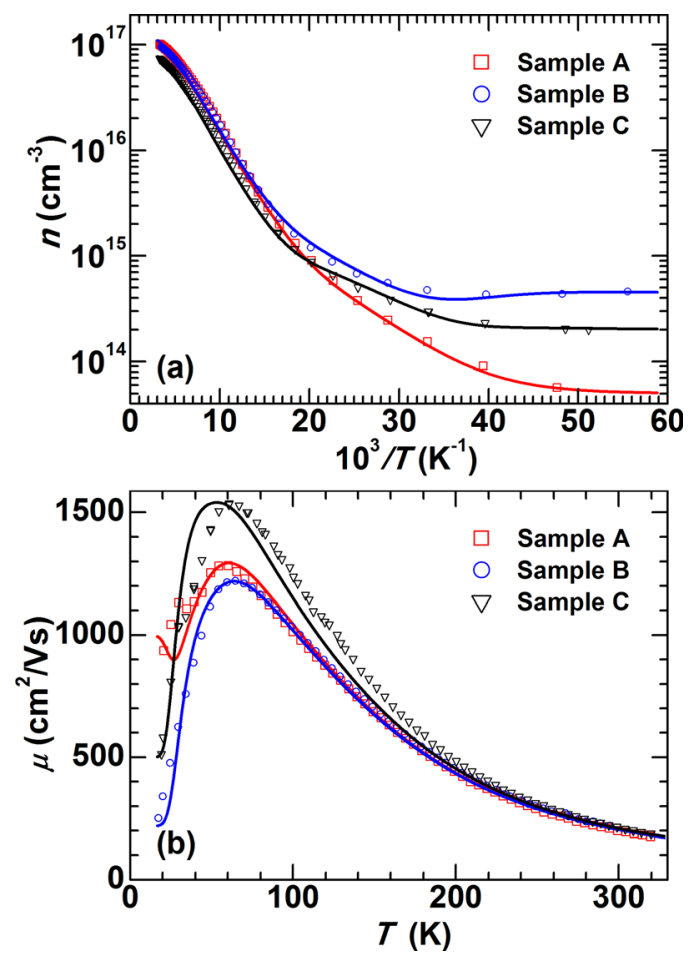

FIG. 3. (Color online) Temperature-dependent (20-320 K) electron carrier concentration (a) and Hall mobility (b) of samples A (squares), B (circles), and $\mathrm{C}$ (triangles). The solid lines are the theoretical fits. 
TABLE II. Fitting parameters of the temperature-dependent Hall-effect analyses.

\begin{tabular}{|c|c|c|c|c|c|c|c|c|}
\hline Sample & $\begin{array}{c}E_{\mathrm{D} 1} \\
(\mathrm{meV})\end{array}$ & $\begin{array}{c}N_{\mathrm{D} 1} \\
\left(10^{17} \mathrm{~cm}^{-3}\right)\end{array}$ & $\begin{array}{c}E_{\mathrm{D} 2} \\
(\mathrm{meV})\end{array}$ & $\begin{array}{c}N_{\mathrm{D} 2} \\
\left(10^{15} \mathrm{~cm}^{-3}\right)\end{array}$ & $\begin{array}{c}N_{\mathrm{A}} \\
\left(10^{15} \mathrm{~cm}^{-3}\right)\end{array}$ & $\begin{array}{c}\mu_{\text {surf }} \\
\left(\mathrm{cm}^{2} / \mathrm{Vs}\right)\end{array}$ & $\begin{array}{c}n_{\text {surf }} \\
\left(10^{17} \mathrm{~cm}^{-3}\right)\end{array}$ & $\begin{array}{l}d_{\text {surf }} \\
(\mathrm{nm})\end{array}$ \\
\hline A & 47 & 1.3 & 12 & 7.4 & 6.4 & 1000 & 2 & 120 \\
\hline B & 47 & 1.3 & 12 & 9.2 & 7.2 & 230 & 100 & 19 \\
\hline $\mathrm{C}$ & 51 & 0.9 & 12 & 4.4 & 3.4 & 506 & 10 & 87 \\
\hline
\end{tabular}

with a mobility of $\sim 1000 \mathrm{~cm}^{2} / \mathrm{Vs}$, and a relatively low total surface concentration $n_{\mathrm{s} \text {,surf }}=n_{\text {surf }} \times d_{\text {surf }}=2.4 \times 10^{12} \mathrm{~cm}^{-2}$. In sample $B$, the surface scattering is much stronger, since the mobility is much smaller, and the sheet carrier density, $n_{\mathrm{s}}$,surf $=1.9 \times 10^{13} \mathrm{~cm}^{-2}$, is much larger, even though the surface layer is thinner. From the above analyses, we conclude that these changes in the surface layer may be responsible for the significantly decreased spin coherence time in $\mathrm{ZnO}$ after $500^{\circ} \mathrm{C}$-annealing. The spin coherence difference between samples $B$ and $C(\sim 2.3$ versus $\sim 2.0 \mathrm{~ns})$ is small comparing to that between samples $\mathrm{A}$ and $\mathrm{B}(\sim 11.2$ versus $\sim 2.3 \mathrm{~ns}$ ). In sample $C, n_{\mathrm{s}}$,surf $=8.7 \times 10^{12} \mathrm{~cm}^{-2}$, which is also larger than in sample $\mathrm{A}$, and based on a simple comparison of $n_{\mathrm{s}}$,surf values alone, sample $\mathrm{C}$ should have a longer $T_{2}{ }^{*}$ than that of sample B. However, it also may be important that $d_{\text {surf }}$ is larger in sample $\mathrm{C}$ than in sample $\mathrm{B}$, and, thus, the spins spend more time in the relatively poor surface region. The slightly poorer crystallinity of sample C than B may also contribute to the small difference in $T_{2}{ }^{*}$. Based on the PL analyses, ${ }^{17}$ the donor state $N_{\mathrm{D} 1}$ in Table II is associated with hydrogen $(\mathrm{H})$ and group-III elements $(\mathrm{Al} / \mathrm{Ga} /$ In), ${ }^{21,24}$ while the acceptor state $N_{\mathrm{A}}$ is possibly due to $\mathrm{Zn}$ vacancies. ${ }^{17,25-27}$ Loss of $\mathrm{H}$ after annealing is observed for the dominating PL peak red shifts, which is commonly observed in $\mathrm{ZnO}$ samples annealed at temperatures above $500{ }^{\circ} \mathrm{C}^{21}$ The reason of formation of surface conducting layer on top of the bulk $\mathrm{ZnO}$ with decreased mobility and increased shallow-donor concentration after annealing is most likely to be the surface accumulation of group-III elements $(\mathrm{Al} / \mathrm{Ga} / \mathrm{In})$ during annealing, indicated by PL spectra, which is consistent with previous secondary-ion mass spectroscopy studies. ${ }^{20}$ The possible dominating spin de-coherence mechanisms were discussed in the supporting materials (ref. 17).

In summary, time-resolved-Kerr-rotation pump-probe magneto-optical spectroscopy was employed to investigate the spin dynamics in $\mathrm{ZnO}$ single crystal samples before and after annealing. It is observed that the spin coherence time $\left(T_{2}{ }^{*}\right)$ in unannealed $\mathrm{ZnO}$ sample is as long as $\sim 11.2 \mathrm{~ns}$ at 8.5 $\mathrm{K}$, but significantly decreases to $\sim 2.3 \mathrm{~ns}$ after $500^{\circ} \mathrm{C}$ annealing. X-ray rocking curves and atomic force microscopy confirm that the crystallinity and surface roughness do not change appreciably during annealing and, thus, are not responsible for the spin-coherence degradation. Temperaturedependent Hall effect measurements indicate that the annealing-induced spin coherence degradation is likely due to decreased mobility and increased carrier concentration in the thin conducting layer on the surface of the bulk $\mathrm{ZnO}$.

This work was supported by ONR/DMEA (H94003-082-0803) through the Center for Nanomaterials and Nanodevices (CNN). The work of DCL was supported by AFOSR Grant FA9550-10-1-0079 (K. Reinhardt) and NSF Grant DMR0803276 (L. Hess).

${ }^{1}$ D. C. Look, Mater. Sci. Eng., B 80, 383 (2001).

${ }^{2}$ J. Kong, S. Chu, M. Olmedo, L. Li, Z. Yang, and J. L. Liu, Appl. Phys. Lett. 93, 132113 (2008).

${ }^{3}$ S. Chu, M. Olmedo, Z. Yang, J. Y. Kong, and J. L. Liu, Appl. Phys. Lett. 93, 181106 (2008).

${ }^{4}$ L. Li, Z. Yang, J. Y. Kong, and J. L. Liu, Appl. Phys. Lett. 95, 232117 (2009).

${ }^{5}$ Z. Yang, S. Chu, W. V. Chen, L. Li, J. Kong, J. Ren, P. K. L. Yu, and J. Liu, Appl. Phys. Express 3, 032101 (2010).

${ }^{6}$ C. Liu, F. Yun, and H. Morkoç, J. Mater. Sci.: Mater. Electron. 16, 555 (2005).

${ }^{7}$ T. Dietl, H. Ohno, F. Matsukura, J. Cibert, and D. Ferrand, Science 287, 1019 (2000).

${ }^{8}$ Z. Yang, J. L. Liu, M. Biasini, and W. P. Beyermann, Appl. Phys. Lett. 92, 042111 (2008).

${ }^{9}$ Z. Yang, M. Biasini, W. P. Beyermann, M. B. Katz, O. K. Ezekoye, X. Q. Pan, Y. Pu, J. Shi, Z. Zuo, and J. L. Liu, J. Appl. Phys. 104, 113712 (2008).

${ }^{10}$ Z. Yang, W. P. Beyermann, M. B. Katz, O. K. Ezekoye, Z. Zuo, Y. Pu, J. Shi, X. Q. Pan, and J. L. Liu, J. Appl. Phys. 105, 053708 (2009).

${ }^{11}$ S. Ghosh, V. Sih, W. H. Lau, D. D. Awschalom, S.-Y. Bae, S. Wang, S. Vaidya, and G. Chapline, Appl. Phys. Lett. 86, 232507 (2005).

${ }^{12}$ S. Ghosh, D. W. Steuerman, B. Maertz, K. Ohtani, H. Xu, H. Ohno, and D. D. Awschalom, Appl. Phys. Lett. 92, 162109 (2008).

${ }^{13}$ N. Jan $\beta$ en, K. M. Whitaker, D. R. Gamelin, and R. Bratschitsch, Nano Lett. 8, 1991 (2008).

${ }^{14}$ N. J. Harmon, W. O. Putikka, and R. Joynt, Phys. Rev. B 79, 115204 (2009).

${ }^{15}$ J. Tribollet, Eur. Phys. J. B 72, 531 (2009).

${ }^{16}$ L. J. Mandalapu, Z. Yang, and J. L. Liu, Appl. Phys. Lett. 90, 252103 (2007).

${ }^{17}$ See supplemental materials at http://dx.doi.org/10.1063/1.3601869 for experimental details and supplemental discussions.

${ }^{18}$ Z. Yang, H. M. Zhou, W. V. Chen, L. Li, J. Z. Zhao, P. K. L. Yu, and J. L. Liu, J. Appl. Phys. 108, 066101 (2010).

${ }^{19}$ D. C. Look, J. Appl. Phys. 104, 063718 (2008).

${ }^{20}$ D. C. Look, B. Claflin, and H. E. Smith, Appl. Phys. Lett. 92, 122108 (2008).

${ }^{21}$ D. C. Look, G. C. Farlow, P. Reunchan, S. Limpijumnong, S. B. Zhang, and K. Nordlund, Phys. Rev. Lett. 95, 225502 (2005).

${ }^{22}$ V. Srikant and D. R. Clarke, J. Appl. Phys. 81, 6357 (1997).

${ }^{23}$ J. F. Muth, R. M. Kolbas, A. K. Sharma, S. Oktyabrsky, and J. Narayan, J. Appl. Phys. 85, 7884 (1999).

${ }^{24}$ B. K. Meyer, H. Alves, D. M. Hofmann, W. Kriegseis, D. Forster, F. Bertram, J. Christen, A. Hoffmann, M. Straßburg, M. Dworzak, U. Haboeck, and A. V. Rodina, Phys. Status Solidi B 241, 231 (2004).

${ }^{25}$ Z. Yang, D. C. Look, and J. L. Liu, Appl. Phys. Lett. 94, 072101 (2009).

${ }^{26}$ Z. Yang and J. L. Liu, J. Vac. Sci. Technol. B 28, C3D6 (2010).

${ }^{27}$ F. Tuomisto, V. Ranki, K. Saarinen, and D. C. Look, Phys. Rev. Lett. 91, 205502 (2003) 